\title{
LETTERS
}

\section{Idiopathic intracranial hypertension: need to rule out cerebral venous sinus thrombosis}

I thank Drs. Micieli and Micieli for their report on fulminant idiopathic intracranial hypertension, which highlighted the importance of promptly considering interventions like optic nerve sheath fenestration or shunting in the setting of vision loss, rather than just standard medical therapy with acetazolamide. ${ }^{1}$ However, a key caveat in the diagnostic process for idiopathic intracranial hypertension that is worth noting is the need to rule out secondary causes of intracranial hypertension, the most important one being cerebral venous sinus thrombosis, which can exactly mimic the clinical symptoms and examination findings of idiopathic intracranial hypertension. There are critical implications for management, as patients with cerebral venous sinus thrombosis require anticoagulation.

Consequently, the diagnostic criteria for idiopathic intracranial hypertension require a normal neuroimaging result, including venography with no evidence of abnormal meningeal enhancement or venous thrombosis. ${ }^{2}$ This can be accomplished using computed tomography or magnetic resonance imaging with venography, but the latter has the added advantage of also potentially showing supportive features of idiopathic intracranial hypertension such as flattening of the posterior globes, tortuous optic nerves, enlargement of the preoptic optic subarachnoid space, empty sella turcica, or narrowing of the transverse venous sinuses.

The presence of 3 or more of these findings is required to make the diagnosis of suspected idiopathic intracranial hypertension in the absence of papilledema or sixth nerve palsy, although idio- pathic intracranial hypertension without papilledema is a controversial entity. ${ }^{3}$

\section{Aravind Ganesh MD DPhil}

Neurology resident, Department of Clinical Neurosciences, University of Calgary, Calgary, Alta.; associate fellow, Centre for Prevention of Stroke and Dementia, University of Oxford, Oxford, UK

Cite as: CMAJ 2019 October 7;191: E1109. doi: 10.1503/cmaj.72955

\section{References}

1. Micieli A, Micieli JA. Recovery of vision in fulminant idiopathic intracranial hypertension. CMAJ 2019;191:E639.

2. Friedman DI, Liu GT, Digre KB. Revised diagnostic criteria for the pseudotumor cerebri syndrome in adults and children. Neurology 2013;81:1159-65.

3. Markey KA, Mollan SP, Jensen RH, et al. Understanding idiopathic intracranial hypertension: mechanisms, management, and future directions. Lancet Neurol 2016;15:78-91.

Competing interests: None declared. 